EPJ Web of Conferences 33, 04004 (2012)

DOI: $10.1051 /$ epjconf/20123304004

(C) Owned by the authors, published by EDP Sciences, 2012

\title{
Environmental Effects of Electrically-stressed Sulfur Hexafluoride
}

\author{
Constantine T. Dervos ${ }^{1}$, John A. Mergos ${ }^{1}$, Maria D. Palaiologopoulou ${ }^{1}$ \\ ${ }^{1}$ School of Electrical and Computer Eng., National Technical University of Athens, Greece
}

\begin{abstract}
High Voltage (HV) equipment such as power switches, current or voltage transformers, and flexible $\mathrm{HV}$ transmission lines insulated by pressurized $\mathrm{SF}_{6}$ (or $\mathrm{SF}_{6} / \mathrm{N}_{2}$ mixtures) offer component compactness, high reliability and low maintenance demands compared to all conventionally insulating components (i.e. air, organic solid insulants, and mineral oils). Though $\mathrm{SF}_{6}$ insulation for $\mathrm{HV}$ applications was initially proposed during late ' $60 \mathrm{~s}$, it was spread worldwide rapidly due to offered significant economic advantages, and now $\mathrm{SF}_{6}$ GIS substations dominate the share in electrical networks in densely populated districts. However, it was in mid ' 90 s when the first ecological concerns were brought about the $\mathrm{SF}_{6}$ gas use. These mainly stream out by either of the following facts: (i) $\mathrm{SF}_{6}$ is a strong green-house gas with a global warming potential of almost 25,000 greater than that of $\mathrm{CO}_{2}$ and its molecules exhibit an exceptionally high lifetime in earth atmosphere estimated to vary between 750 and 2500 years, and (ii) when electrically stressed (independent of temperature i.e. either high-power arcs developing at $20,000 \mathrm{~K}$ during the switching actions, or corona discharges developing at $300 \mathrm{~K}$ due to high electric field effects) toxic byproducts may be formed, some having high cyto-toxicities i.e. $\mathrm{S}_{2} \mathrm{~F}_{10}$, oxyfluorides, $\mathrm{H}_{2} \mathrm{~S}$ and $\mathrm{HF}$.
\end{abstract}

\section{Introduction}

This work provides information concerning possible global environmental implications and personnel safety aspects that should be considered during the commercial uses of sulphur hexafluoride. Gas insulated systems are now a major component of power transmission and distribution networks all over the world. Gas insulated switchgear (GIS) is exclusively used above $400 \mathrm{kV}$, having all components interconnected and insulated via compressed $\mathrm{SF}_{6}$ (i.e. circuit breakers, disconnectors, grounding switches, bushbars, potential transformers, power transformers, cable insulation etc.) [1-3]. Due to their compactness and steel shielding, they offer significant savings in land use, are aesthetically acceptable, have relatively low radio and audible noise emissions, and enable substations to be installed in cities very close to the loads.

Sulphur hexafluoride is an anthropogenically produced slow reacting gas with a relatively high molecular weight. It exhibits excellent arc extinction properties and this gives rise to its high applicability in power technology. In its normal state it is chemically inert, non-toxic and nonflammable. Because of its inertness and non-toxic characteristics it has been treated as an 
environmentally safe and acceptably non-toxic material, in the sense that it does not react unfavorably with the biomass. However, when dissociated under high-pressure conditions in an electrical discharge the pure $\mathrm{SF}_{6}$ may readily reform toxic byproducts [4-5].

There are no known natural sources of $\mathrm{SF}_{6}$ on earth. $\mathrm{SF}_{6}$ exhibits exceptionally long life times in the earth atmosphere [6-7]. The atmospheric lifetime of $\mathrm{SF}_{6}$ when estimated on the basis of the negative ion model, is found to range between 800 and 2500 years [8-9]. $\mathrm{SF}_{6}$ is an efficient absorber of infrared radiation, particularly in the wave number range from 915 to $960\left(\mathrm{~cm}^{-1}\right)$ [10]. The effective trapping of infrared radiation results in an increase of the average temperature of the atmosphere due to balance shifting between the incoming and outgoing radiation. The effect is known as the 'greenhouse effect' and the responsible gases for it are frequently referred as 'greenhouse gases". Such gases are both man-made and naturally occurring, e.g. $\mathrm{H}_{2} \mathrm{O}, \mathrm{CO}_{2}, \mathrm{CH}_{4}$, $\mathrm{N}_{2} \mathrm{O}$ (which could also be increased during pollution episodes), or purely man-made gases, e.g. fully fluorinated compounds (FFC). Therefore, the global warming effect has two contributors: The natural, originating by naturally occurring gas concentrations and the enhanced, introduced by concentration enhancements or anthopogenically produced compounds. It is now known that $\mathrm{SF}_{6}$ is a radiatively active [11] and a potent greenhouse gas [12]. Its global warming potential is 25000 times greater than that of $\mathrm{CO}_{2}$ [13-14]. The relative contribution of $\mathrm{SF}_{6}$ to global warming was estimated in late 90 s to be only $0.01 \%$ and unlike other environmental pollutants, there is no evidence that $\mathrm{SF}_{6}$ contributes to stratospheric ozone depletion [15]. Because $\mathrm{SF}_{6}$ is now extensively used, concerns have been raised about its long term environmental impact [16]. If production and leak rates of $\mathrm{SF}_{6}$ are maintained at current rates, it is expected that in 80 years from now, its relative contribution to global warming could exceed $0.1 \%$. Due to its enormous global warming potential [17], $\mathrm{SF}_{6}$ is being systematically monitored by a number of air sampling programs [18-19]. These may include high resolution latitudinal profiles over the oceans, weekly flask samples from remote, globally distributed sites, hourly in situ measurements in rural [20] or industrial areas, and a series of archived air samples. The work presented in this paper provides analytical results of toxic byproducts formations obtained by Quadrupole Mass Spectrometry in the $\mathrm{SF}_{6}$ gas matrix of HV GIS power substations. The gas compartments were examined after developing electrical faults (i.e. corona discharge in $150 \mathrm{kV}$ bus-bars, overheating effects on loosely attached stationary connectors, and a high power arc developed as a result of contaminated gas compartment)

\section{Toxic byproducts of $\mathrm{SF}_{6}$ in the working environment}

The reliability of the insulating gas of six $150 \mathrm{kV}$ GIS power substations operated continuously over a period of thirty years has been investigated. As shown in Figure 1, the design of the substations incorporated single phase double pressure dead tank switches commonly produced in late 60's. During all these years periodic inspection and maintenance (i.e. 13X filter substitution, gas dehydration and gas room cleaning) had been primarily based upon water dew point measurements. Recently, quality control and assurance of the insulating gas has been exploited by in situ mass spectrometry and byproduct production yield determination. Such measurements can be performed while the substation is in normal operation, thus offering operational safety and exact maintenance prognosis. 


\section{$2^{\text {nd }}$ European Energy Conference}

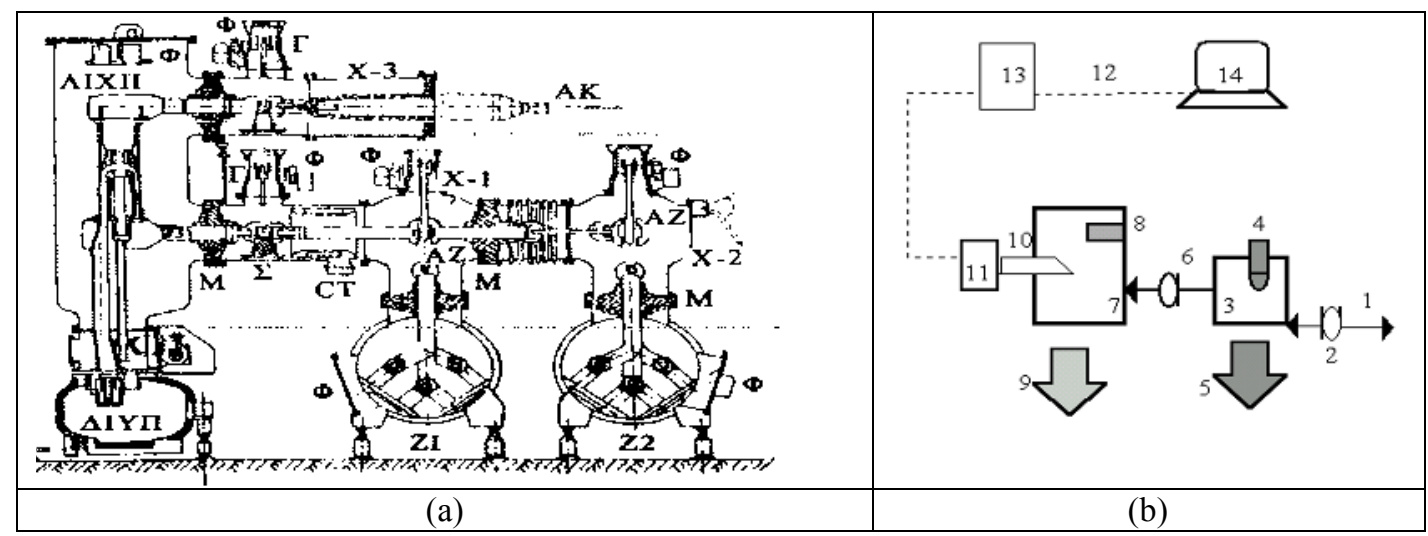

Fig 1. Typical view of: (a) the examined GIS plant and (b) the gas analysis measuring system.

$\begin{array}{cl}\text { Z1 Z2 } & \text { Bus I Bus II } \\ \text { X-1 } & \text { Room 1 } \\ \text { X-2 } & \text { Room 2 } \\ \text { X-3 } & \text { Room 3 } \\ \Phi & \text { Filter position } \\ \Gamma & \text { Earth switch } \\ \text { CT } & \text { Current transformer } \\ \text { AK } & \text { Cable bushing }\end{array}$

$\begin{array}{cl}\text { A } & \text { Disconnecting switch } \\ \Sigma & \text { Support insulator } \\ \text { M } & \text { Conical insulators } \\ \Delta \text { IXI } & \text { Power switch low pressure } \\ \Delta \text { IYI } & \text { Power switch high pressure } \\ 1 & \text { Flexible stainless steel } \\ & \text { interconnect with pressure gauge } \\ 2 & \text { gas dozing valves at either end } \\ 3 & \text { prechamber } \\ 4 & \text { pressure gauge }\left(2000-10^{-3} \text { mbar }\right)\end{array}$

5 high vacuum pumping unit

6 needle valve

7 ultra high vacuum chamber

8 cold cathode ion gauge

9 turbo-drug pumping unit

10 quadrupole mass analyzer

11 ion current amplifier (SEM)

12 data bus

13 quadrupole electronics

14 result storage and data bank PC

Gas samples could be obtained from all rooms of the GIS plant, Figure 1, Partial pressure measurements were performed by Quadrupole Mass Spectrometry (QMS). The employed analyzer head consisted of (a) an axial ion source where molecules could be ionized by $100 \mathrm{eV}$ electron beam, (b) a quadrupole mass filter unit, operating in the atomic mass range between $1 \leq \mathrm{amu} / \mathrm{q} \leq 200$, and (c) a Faraday collector offering minimum ion current detection $10^{-14} \mathrm{~A}$. Exact ion concentrations were determined by the corresponding ion current values in the obtained spectra, according to the following equation:

$$
\operatorname{ppm}(\text { ion })=\mathrm{I}(\text { ion }) \cdot 10^{6} / \mathrm{P}(\mathrm{mbar}) \cdot \mathrm{E}(\mathrm{amu} / \mathrm{q})
$$

where ppm(ion) is the ion concentration in ppm, I(ion) the detected ion current (A), $\mathrm{P}(\mathrm{mbar})$ the total pressure -measured in mbar- in the analyzing system, and $\mathrm{E}(\mathrm{amu} / \mathrm{q})$ the quadrupole sensitivity $(\mathrm{A} / \mathrm{mbar})$ at the examined atomic mass unit over charge $(\mathrm{amu} / \mathrm{q})$ position.

The characteristic peaks of singly ionized fragments of pure dry $\mathrm{SF}_{6}$ are encountered at the following amu/q positions: $\mathrm{F}^{+}=19,{ }^{32} \mathrm{~S}^{+}=32,{ }^{32} \mathrm{SF}^{+}=51,{ }^{32} \mathrm{SF}_{2}{ }^{+}=70,{ }^{32} \mathrm{SF}_{3}^{+}=89,{ }^{32} \mathrm{SF}_{4}{ }^{+}=108$, and ${ }^{32} \mathrm{SF}_{5}{ }^{+}=127$. Doubly ionized $\mathrm{SF}_{6}$ fragments may be detected at the following amu/q positions: ${ }^{32} \mathrm{SF}^{++}=25.5,{ }^{32} \mathrm{SF}_{2}{ }^{++}=35,{ }^{32} \mathrm{SF}_{3}{ }^{++}=44.5,{ }^{32} \mathrm{SF}_{4}^{++}=54$, and ${ }^{32} \mathrm{SF}_{5}^{++}=63.5$. Singly ionized fragments formed by the ${ }^{34} \mathrm{~S}$ isotope, having natural abundance $4.2 \%$, are shifted by two mass units from the corresponding ${ }^{32} \mathrm{~S}$ ions. For the doubly ionized fragments this difference turns out to be only one mass unit. ${ }^{32} \mathrm{SF}_{3}{ }^{+}$and ${ }^{32} \mathrm{SF}_{5}{ }^{+}$provide large characteristic peaks and therefore, suitable mass tracking sites for $\mathrm{SF}_{6}$ detection in air. For the employed analyzing system, the minimum detection capability was of the order of $10 \mathrm{ppb}$.

In the presence of an electrical discharge such as an arc, spark, or corona, a portion of the $\mathrm{SF}_{6}$ decomposes into lower fluorides of sulphur which can react to form a number of chemically active byproducts. For the electrically stressed $\mathrm{SF}_{6}$, the most frequently mentioned molecular ion 
byproducts $\left({ }^{32} \mathrm{~S}\right.$ isotope $)$ are detected at the following amu/q positions: $\mathrm{H}_{2} \mathrm{O}^{+}=18, \mathrm{~N}_{2}^{+}=28, \mathrm{HF}^{+}=$ $20, \mathrm{H}_{2} \mathrm{~S}^{+}=34, \mathrm{CO}_{2}^{+}=44, \mathrm{SOF}^{+}=67, \mathrm{SOF}_{2}^{+}=86, \mathrm{SOF}^{+}=124, \mathrm{SO}_{2} \mathrm{~F}^{+}=83, \mathrm{SO}_{2} \mathrm{~F}_{2}^{+}=102, \mathrm{SO}_{2} \mathrm{~F}_{4}^{+}$ $=140$, and $\mathrm{S}_{2} \mathrm{~F}_{10}{ }^{+}=254$. Much effort has been spent in identifying the species, the generation rates, and some of their properties, under laboratory or practical operating conditions in GIS power systems.

Fig 2 presents typical spectra from GIS Room 1 (of Fig 1) monitored during plant operation before and after maintenance. The reduction of the $\mathrm{CO}_{2}$ concentration from $5 \mathrm{ppm}$ to sub ppm levels $(100 \mathrm{ppb})$ as a result of sorbent substitution is evident. It should be noted that for $\mathrm{CO}_{2}$ detection in $\mathrm{SF}_{6}$ matrix the characteristic peaks between $\mathrm{CO}_{2}$ and $\mathrm{SF}_{3}{ }^{++}$differ only by $0.5 \mathrm{in}$ amu/q scale.

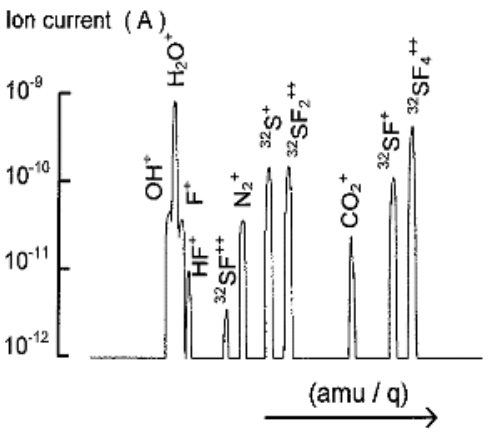

(a)

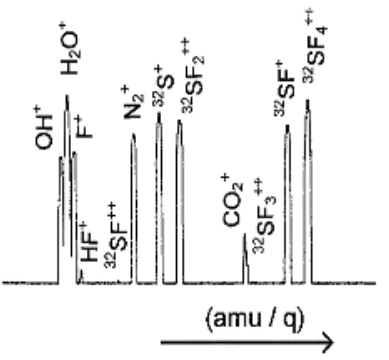

(b)

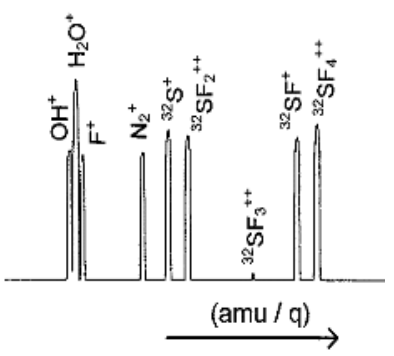

(c)

Fig 2. The effect of filter substitution on $\mathrm{CO}_{2}$ concentration levels as a function of time in GIS Room 1 incorporating the current transformer. (a) before filter substitution; water dew point $-23^{\circ} \mathrm{C}$, (b) two days following filter substitution; water dew point $-37.8^{\circ} \mathrm{C}$ and (c) 60 days following filter substitution; water dew point $-38^{\circ} \mathrm{C}$. Concentrations of $\mathrm{SF}_{6}$ fragments are reduced under identical measuring conditions.

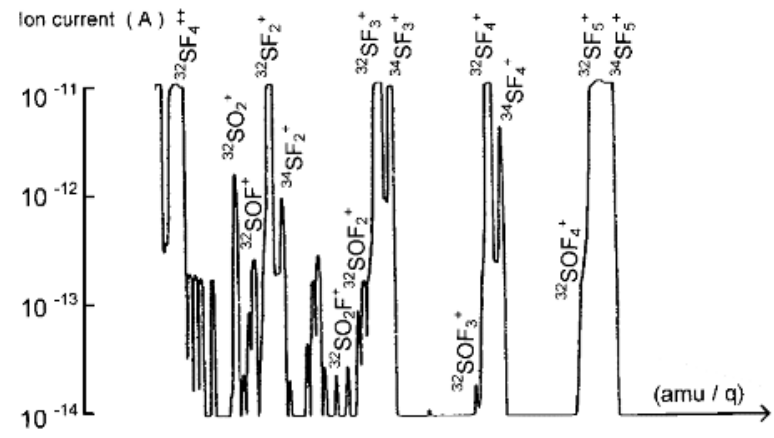

Fig 3. Oxyfluoride detection levels in the volume of the switch during a switch operation.

Finally, the oxyfluoride levels may be directly detected at higher current sensitivities, as shown in Fig 3. The displayed results were selected from the low pressure power switch room, following a switch operation. Greater concentrations of detected oxyfluorides were recorded for the following amu/q positions: $\mathrm{SOF}^{+}=67, \mathrm{SOF}_{2}^{+}=86, \mathrm{SOF}_{3}^{+}=105, \mathrm{SOF}_{4}^{+}=124, \mathrm{SO}_{2} \mathrm{~F}^{+}=83$ and $\mathrm{SO}_{2}^{+}=64$. 


\section{$2^{\text {nd }}$ European Energy Conference}

Figure 4 provides characteristic quadrupole mass analysis spectrum of the gas in a compartment subjected to a thermal-runaway induced power arc. The increased gaseous constituents of byproducts in the $\mathrm{SF}_{6}$ gas matrix were: $\mathrm{C}_{12}{ }^{+}, \mathrm{O}^{+}, \mathrm{HF}^{+}, \mathrm{S}^{+}, \mathrm{C}_{3} \mathrm{H}_{4}^{+}, \mathrm{SO}^{+}, \mathrm{SO}_{2}^{+}, \mathrm{SOF}^{+}, \mathrm{SO}_{2} \mathrm{~F}^{+}$. The gas had a "rotten-egg" smell. The specific sample was selected from a $400 \mathrm{kV}$ Gas Insulated Transmission Line that developed an internal fault in a triple point synergy position, i.e. the location where a solid insulator, a metallic conductor and the insulation gas co-exist in working synergy. The compartment is shown in Fig. 3a where the suspending insulator developed electrical erosion (Fig 3b) and the internal chamber walls were locally melted in the positions of the roots of the internal power $\operatorname{arcs}($ Fig 3c).

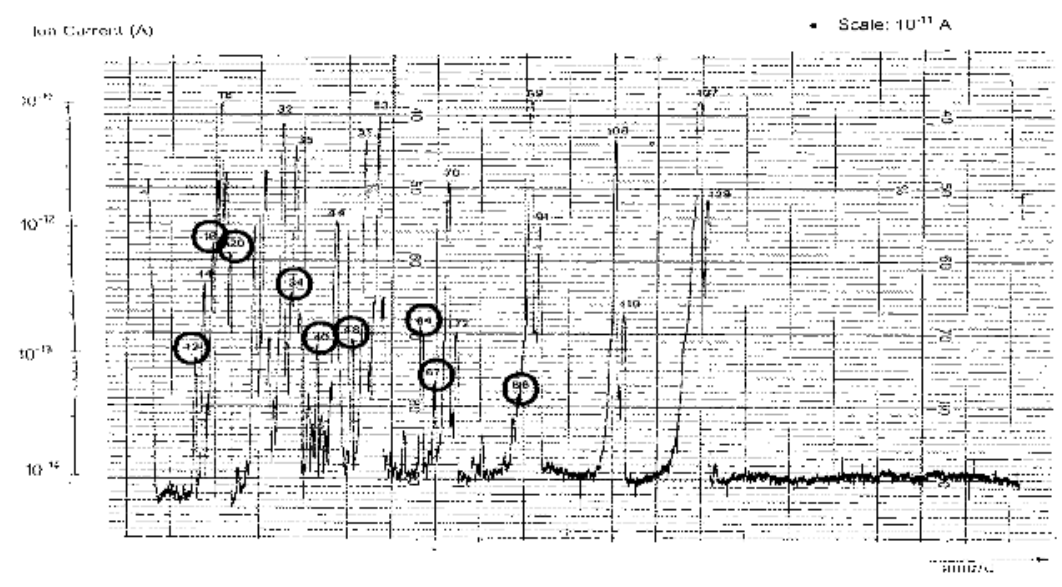

Fig 4. Mass spectra in the amu/q range between 1 and 200 of the gas sample collected from the bus-bar chamber after the high power arc development. A logarithmic ion current scale is used for result presentation and the ion current values vary between $10^{-14}$ and $10^{-11} \mathrm{~A}$.

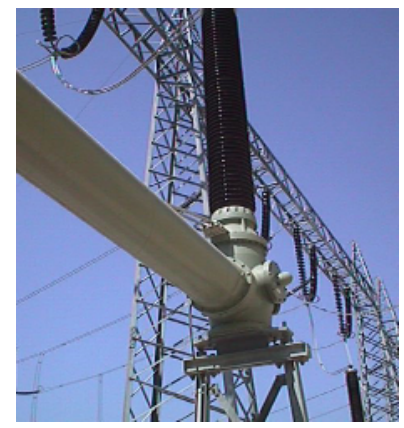

(a)

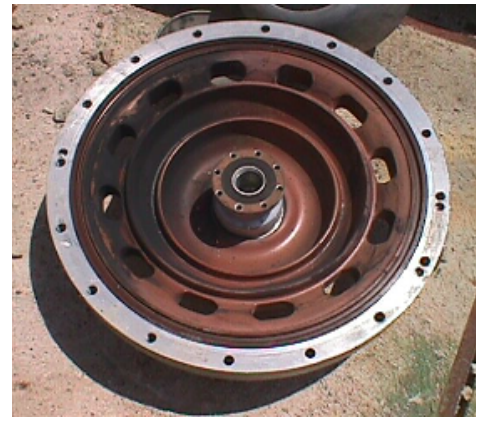

(b)

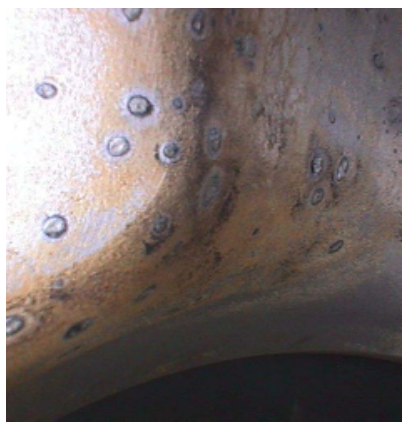

(c)

Fig 3. Arc discharge generated due to triple point synergy problem in the chamber, led to surface damage of the suspending insulator and electrochemical erosion of the internal chamber walls. 
The most important toxic byproducts, as well as their common concentrations observed during the working cycle of $\mathrm{SF}_{6}$ as a gaseous dielectric, are summarized in the Tables 1, 2 [21].

Table 1. $\mathrm{SF}_{6}$ decomposition byproducts and their typical concentrations during repeated sparking. A $16 \mathrm{~kJ}$ total energy deposition in $70 \mathrm{~cm}^{3} \mathrm{SF}_{6}$ gas is examined

\begin{tabular}{|c|c|}
\hline Product & $\begin{array}{c}\text { Approximate concentration } \\
\text { (\% by volume) }\end{array}$ \\
\hline $\mathrm{SOF}_{2}\left(\mathrm{SF}_{4}\right)$ & 0.5 \\
\hline $\mathrm{SOF}_{4}$ & 0.085 \\
\hline $\mathrm{SF}_{4}$ & 0.085 \\
\hline $\mathrm{S}_{2} \mathrm{~F}_{10}$ & 0.025 \\
\hline $\mathrm{SO}_{2} \mathrm{~F}_{2}$ & 0.006 \\
\hline $\mathrm{SO}_{2}$ & 0.002 \\
\hline $\mathrm{HF}$ & 1.0 \\
\hline
\end{tabular}

Table 2. Cytotoxicity of $\mathrm{SF}_{6}$ decomposition products derived by culture cell systems. Data are not provided for cases where insufficient cell disruption was produced at any concentration tested to derive LC50 values

\begin{tabular}{|c|c|c|}
\hline Compound & LC50\% (4h) & Slope of Cyto-toxicity curve \\
\hline $\mathrm{S}_{2} \mathrm{~F}_{10}$ & 0.008 & 10000 \\
\hline $\mathrm{SOF}_{4}$ & 0.8 & 227 \\
\hline $\mathrm{SO}_{2} \mathrm{~F}_{2}$ & 0.35 & 200 \\
\hline $\mathrm{SF}_{4}$ & 1.5 & 32 \\
\hline $\mathrm{SOF}_{2}$ & 1.5 & 27 \\
\hline $\mathrm{SO}_{2}$ & - & - \\
\hline $\mathrm{HF}$ & - & 1 \\
\hline $\mathrm{S}_{2} \mathrm{~F}_{10}$ & 0.5 & $0.04-0.37$ \\
\hline
\end{tabular}

\section{Recommendations and Conclusions}

It is true that equipment incorporating $\mathrm{SF}_{6}$ has a demonstrated value for society. However, the environmental risks (either in the global atmosphere or in the working environment) strongly dictate that improved handling procedures and innovative designs of GIS constructions will have to be adopted to minimize leaks to the atmosphere. CIGRE recommends that at the end of life of $\mathrm{SF}_{6}$ equipment, the electrically stressed gas will either have to be recycled, or reduced to environmentally compatible end-products. $\mathrm{SF}_{6}$ can be destroyed by thermal decomposition in industrial waste treatment furnaces at elevated temperatures $\left(>1100^{\circ} \mathrm{C}\right)$. In this process the 


\section{$2^{\text {nd }}$ European Energy Conference}

constituents of $\mathrm{SF}_{6}$, sulphur and fluorine, are converted into naturally occurring materials $\mathrm{CaSO}_{4}$ (gypsum) and $\mathrm{CaF}_{2}$ (fluorspar) by reacting with $\mathrm{CaCO}_{3}$ (calcite). The excess of $\mathrm{CaCO}_{3}$ is required to assure the reaction with any $\mathrm{HF}$ or $\mathrm{H}_{2} \mathrm{~S}$ that may be produced in the furnace by the thermal decomposition of $\mathrm{SF}_{6}$. Gypsum and fluorspar can be land filled or possibly used as raw materials in other processes.

The problems related to $\mathrm{SF}_{6}$ and the power industry are not without solutions and may eventually lead to new opportunities (e.g. in-situ recycling or disposal; development of alternative gaseous insulators; or even, alternative high voltage technologies). Besides current efforts and recommendations to control the release of electrically stressed $\mathrm{SF}_{6}$, the introduction of additional environmental standards concerning recycling procedures or on-site gas purity control have yet to become available. A comprehensive systematic on-line monitoring and in situ analysis of the gas concentrations would be beneficial towards:

(i) personnel safety; toxicity control of the $\mathrm{SF}_{6}$ gas matrix could be based upon disulphur decafluoride or oxyfluoride detection levels.

(ii) locating leaks; and help to curtail undesirable release to the atmosphere, and

(iii) component reliability and assurance; systematic examination of certain byproduct concentrations can be used as a maintenance prognosis tool (e.g. the presence of high $\mathrm{CO}_{2}$ levels in the $\mathrm{SF}_{6}$ matrix of a GIS plant singularly identifies filter sorption saturation, while the presence of metal fluorides [22] possibly originating from the erosion of field smoothing devices should be immediately removed as it may induce surface fatigue (or damage) on the solid insulants of the installation. Thus, the on-line monitoring and analysis techniques, although substantially increase the regular running cost of the equipment, could be proved to be beneficial for the power industry.

\section{REFERENCES}

[1] W.T. Shugg, Handbook of Electrical and Electronic Insulating Materials (IEEE Press, New York, Second Edition, 433-452, 1995)

[2] D. Kopejkova, T. Molony, S Kobayashi, I.M. Welch, CIGRE, paper 23, 1091 (1992)

[3] A.Elliker, H. Karrenbauer, A. Lerondeau, CIGRE, paper 13, 303 (1990)

[4] A.Baker, R. Dethlefsen, J. Dodds, N. Oswalt, P. Vouros, EPRI Report No. EL-1646 (1980)

[5] F.Y.Chu, I. Sauers, G.D. Griffin, in IEEE International Symposium on Electrical Insulation, New York, 131-134 (1988)

[6] P.K. Patra, S. Lal, B.H. Subbaraya, C.H. Jackman, P. Rajaratnam , J. Geophys. Res., 100, 8855-8859 (1997)

[7] D.J. Wuebbles, A.K Jain, EPA Conf. Proc. Report, 8-38 (1995)

[8] R.A. Morris, T. A. Miller, A.A. Viggiano, J.F. Paulson, S Solomon, G. Reid, J. Geophys. Res., 100, 1287-1294 (1995)

[9] A.R.Ravishankara, S. Solomon, A.A. Turnipseed, R.F. Warren, Science, 259, 194-199 (1993)

[10] D. Edelson, K.B. Mc. Affe, J. Chem. Phys., 19, 1311-1314 (1951)

[11] P.S. Bakwin, D.F.Hurst, P.P. Tans, J.W. Elkins, J. Geophys. Res., 102, 15915-15925 (1997)

[12] L.S. Geller, J.W. Elkins, J.M. Lobert, A.D. Clarke, Geophys. Res. Lett., 24, 675-678 (1997)

[13] R.J. Van Brunt, IEEE International Conference on Plasma Science, Boston, MA, 96CH35939, 145 (1996)

[14] Intergovernmental Panel on Climate Change (IPCC), Radiative forcing of climate change. Report of the Scientific Assessment Working Group of IPCC, 26-28. (1994)

[15] L. Niemeyer, F.Y. Chu, IEEE Trans. Elec. Insul., 27, 1844 (1992)

[16] L.G. Christophorou R. J and Van Brunt, National Institute of Standards and Technology Report NISTIR 5685, (1995) 
[17] J.T. Houghton, L.G. Meira Filho, B.A. Callander, N. Harris, A. Kattenberg, K. Maskell, Intergovernmental Panel on Climate Change (IPCC), Cambridge University Press, Cambridge, New York, 22 (1996)

[18] M.K.W Ko, Nien Dak Sze, Wang Wei-Chyung, G. Shia, A. Goldman, F.J. Murcray, D.G. Murcray, C.P. Rinsland, J. Geophys. Res., 1, 98, 10499-10507 (1993)

[19] M Maiss, I. Levin, Geophys. Res. Lett., 21, 569-572 (1994)

[20] D.F. Hurst, P.S. Bakwin, R.C. Myers, J.W. Elkins, J. Geophys. Res., 102, 8825-8835 (1997)

[21] C. Dervos, P. Vassiliou, Journal of AWMA, 50, pp137-141 (2000).

[22] C.T. Dervos, P. Vassiliou and J.A. Mergos, J.Phys. D, Appl. Phys. 40 ,6942-6952 (2007). 